\title{
The Combined Value of Faecal Haemoglobin and Calprotectin in Diagnosis of Colorectal Cancer in Symptomatic Patients Referred to Colonoscopy
}

\author{
Vincy Eklöf ${ }^{1}$, David Lundgren², Pontus Karling², Maria L Wikberg ${ }^{1}$, Sofia Edin ${ }^{1}$, Anna Löfgren-Burström¹, \\ Jörgen Rutegård ${ }^{3}$ and Richard Palmqvist ${ }^{1 *}$ \\ ${ }^{1}$ Department of Medical Biosciences/Pathology, Umeå University, Sweden
}

${ }^{2}$ Department of Public Health and Clinical Medicine, Umeå University, Sweden

${ }^{3}$ Department of Surgical and Perioperative Sciences, Umeå University, Sweden

*Corresponding author: Richard Palmqvist, Department of Medical Biosciences/

Received Date: September 12, 2019

Pathology, Umeå University, Sweden.

\section{Abstract}

Aim: To investigate the diagnostic value of a combined analyses of faecal immunological haemoglobin (FIT) and faecal calprotectin (FC) in detection of colorectal cancer (CRC)

Methods: Out-patients ( $n=1440)$ referred to the endoscopy unit were analysed for FIT and FC in stool samples collected before the colonoscopy bowel preparation. The samples were collected from one defecation by the patients at home. Patients with IBD were excluded leaving stool samples from 1133 patients for further analyses. FIT was analysed using the immunological Analyse F.O.B Test and FC was analysed using the CALPRO ${ }^{8}$ Calprotectin Elisa Test. Sensitivity and specificity to detect CRC was calculated for the individual tests, as well as for combined FIT/FC tests.

Results: Out of the included patients, 38 were diagnosed with CRC, 9 with high grade dysplasia (HGD), and 133 with low grade dysplasia (LGD). FIT was analysed in 673 (59.4\%), FC in 1021 (90.1\%) and both FIT and FC in 561 (49.5\%) patients. A ROC curve analysis showed that the most accurate cut-off level for FC in detecting CRC in our study was $105.5 \mu \mathrm{g} / \mathrm{g}$. The sensitivity for CRC when using FIT, FC (cut-off > $100 \mu \mathrm{g} / \mathrm{g}$ ) and the combination of FIT and FC (at least one positive test) was $65.5 \%, 74.1 \%$ and $94.4 \%$, respectively. The corresponding specificity was $84.8 \%, 74.9 \%$ and $68.3 \%$, respectively.

Conclusion: Combined analyses of FIT and FC improved sensitivity for detection of CRC. Further studies in larger cohorts are required to find the optimal cut-off levels for different combinations of tests.

Keywords: Colorectal cancer; F-Calprotectin; F-Hb: Faecal markers; Screening markers

\section{Introduction}

Colorectal cancer (CRC) is the third most commonly diagnosed cancer worldwide and has a considerable impact on both the individual and the health care system. The majority of patients with CRC have their initial consultation in primary care [1]. However, the symptoms of CRC often present late. In addition, a vast majority of patients seeking primary care for symptoms associated with CRC (rectal bleeding, a change in bowel habits, diarrhoea, constipation and abdominal pain) are not diagnosed with CRC [2-4]. Therefore, general screening programs among individuals at average risk for CRC, along with guidelines for urgent referral, are implemented widely to reduce mortality of the disease $[5,6]$. However, there is still a need for improved screening strategies for CRC $[4,7,3]$. The recommended "gold standard" screening tool for CRC today is endoscopic examination, such as sigmoidoscopy or colonoscopy, but such examinations are resource-demanding, highly costly and inconvenient for the patients [8-11]. The most important factor in screening is patient adherence, and therefore annual faecal occult blood tests have been suggested as an alternative to endoscopy in CRC screening [7]. Analysis of faecal haemoglobin (F-Hb) using either guaiac-based (gFOBT) tests or, more recently, immunological (FIT) tests [12] is commonly used as a primary screening tool, since it requires no preparation, is cost-effective, and relatively convenient for the patient [13]. A positive F-Hb test is an indication of bleeding in the gastrointestinal (GI) tract, which could be caused 
by a premalignant adenoma or an adenocarcinoma. A healthy individual loses in average 1-2 $\mathrm{ml}$ of blood per day in the GI-tract. A test for F-Hb therefore needs to be adjusted for this normal blood loss. Another limitation of F-Hb tests, in the ability to discriminate between blood loss associated with a neoplastic lesion from that of normal blood loss in the GI-tract, is that the neoplastic lesions often bleed intermittently [14-16].

The sensitivity of different F-Hb tests vary depending on method and number of repeated tests $[17,18]$. FIT is more specific than gFOBT in detecting bleeding from colon, since it can distinguish human haemoglobin $[17,16,18]$. Dependent on the analysis method and the cut-off used, a single FIT test shows a sensitivity of 66$82 \%$ and a specificity of $92-98 \%$ [19-21]. No additional diagnostic value has been found for repeated testing using FIT [22,23]. FIT tests are thus highly specific but have limited sensitivity in detecting neoplastic lesions in the colon, therefore combined tests using additional faecal markers have been suggested $[24,7,25]$. One interesting marker is feacal calprotectin (FC). Calprotectin is a Ca- and Zn-binding protein, which is located in the neutrophil leucocytes. FC is protease resistant, stable in the GI-tract [26] and widely used in diagnosis and evaluation of inflammatory bowel disease (IBD). Recently it has also been evaluated as a potential marker in the context of cancer screening, since it has been shown that the level of FC is increased in stool of patients with CRC [26-31] and is decreased after CRC surgery [32].

The rationale of combining analyses of $\mathrm{F}-\mathrm{Hb}$ and $\mathrm{FC}$ is that a combined test can detect bleeding in the GI-tract as well as inflammatory changes associated with CRC. In addition, FC exhibit less variation within patients with CRC than F-Hb [33]. The aim of the present investigation was to assess the value of a combined FIT and FC test in detection of colorectal neoplasia. We hypothesized that a combination of a single FIT and FC test can improve sensitivity in detection of CRC in comparison to using FIT alone. The prospective study was performed in patients referred for colonoscopy to the endoscopy unit on suspicion of CRC. At the time of the study, there was no general screening program for CRC in the catchment area.

\section{Materials and Methods}

\section{Study cohort}

This prospective study is based on a patient cohort recruited during 2008-2013 at the University Hospital, Umeå, Sweden. Outpatients scheduled for colonoscopy were invited to participate in the study. Indications were changes of bowel habits and/or alarm features (e.g. weight loss) and/or signs of gastrointestinal bleeding (anemia, iron deficiency, positive FIT or visible bleeding). Exclusion criteria were planned colonoscopy less than one week ahead and low performance status and/or cognitive dysfunction. The study protocol was approved by the Research Ethics Committee of Umeå university, Umeå, Sweden (Dnr 08-184M and 07-045M) and the study has been performed in accordance with the ethical standards laid down in the Declaration of Helsinki. All patients gave their informed consent prior to their inclusion in the study. Study information, informed consent form and tubes for stool sample collection were sent to the patients together with the invitation for the clinical colonoscopy examination. All participants were asked to leave faecal samples before the colonoscopy cleansing procedure started. The endoscopy was performed in clinical routine. Lesions found were biopsied or if indicated removed. The outcome of the endoscopy was routinely recorded in the patient medical records. All clinical findings were retrospectively verified by studying the patient medical records, including the pathologist reports. For patients with several lesions, the most severe lesion was recorded. All patients and all medical personal, including endoscopists and pathologists, were blinded for the results of the faecal tests.

\section{Selection of study patients}

Of the out-patients referred for colonoscopy during the study period, 1440 signed an informed consent. One hundred and fifteen patients were excluded due to missing faecal samples and 192 patients diagnosed with IBD were also excluded in the present study. After inclusion and exclusion criteria were fulfilled, 1133 patients remained in the final analysis.

\section{Stool collection and analyses}

Three tubes were sent to the patients, one for FC analysis, one for FIT analysis, and one containing $5 \mathrm{ml}$ stabilization buffer, RNAlater® (Applied Biosystems, Life Technology, Stockholm, Sweden). The collected samples were stored in room temperature in maximally seven days before taken care of. The tubes for FC were sent directly to the accredited Clinical Chemistry Laboratory at the University Hospital in Umeå for analysis. FIT was analysed as described below.

\section{Faecal markers}

FIT was analysed using the immunological Analyse F.O.B Test (FIT) (ANL products AB, Sweden), according to manufacturer's instructions. The FIT test was scored as positive or negative, with a positive test indicating $>40 \mathrm{ng} / \mathrm{ml}$ of human haemoglobin. The FC samples were sent to the accredited Department of Laboratory Medicine, Clinical Chemistry, Umeå University Hospital, and analysed using the CALPRO ${ }^{\circledR}$ Calprotectin ELISA Test (ALP) according to the manufacturer's instructions (Calpro AS, Norway). The measuring range for FC is between $20 \mu \mathrm{g} / \mathrm{g}$ and $10000 \mu \mathrm{g} / \mathrm{g}$. Values out of range were recorded as $<20 \mu \mathrm{g} / \mathrm{g}$ and $>10000 \mu \mathrm{g} / \mathrm{g}$.

\section{Statistical analysis}

Differences in baseline characteristics and study variables were compared by Fischer's test or $\chi 2$ tests. Sensitivity and specificity for continuous FC were calculated using ROC-curve analysis, giving area under curve (AUC). Sensitivity and specificity, positive predictive value (PPV) and negative predictive value (NPV) at group level for FIT and FC were calculated. All statistics was calculated using SPSS version 23.0 (Chicago, Illinois, USA).

\section{Results}

\section{Patient characteristics}

Out-patients referred to the endoscopy unit were analysed for FIT and FC in stool samples collected in parallel before the bowel 
preparation. Of the 1133 patients included in the study, FIT was analysed in 673 (59.4\%), FC in 1021 (90.1\%) and both FIT and FC in $561(49.5 \%)$ patients (Table 1$)$. The included patients had an equal gender distribution and a median age of 65.4 years. Overall, 827 (73.0\%) of the patients were recorded as normal with no significant findings. Adenocarcinoma and high-grade dysplasia were recorded in 47 patients (4.1\%). The distribution of the pathological findings is shown in (Table 1).

Table 1: Clinical characteristics of the study participants $(n=1133)$.

\begin{tabular}{|c|c|}
\hline \multicolumn{2}{|l|}{ n (\%) } \\
\hline Age & \\
\hline$<59$ & $374(33.0)$ \\
\hline $60-69$ & $382(33.7)$ \\
\hline $70-79$ & $307(27.1)$ \\
\hline$>80$ & $70(6.2)$ \\
\hline \multicolumn{2}{|l|}{ Sex } \\
\hline Men & $542(47.8)$ \\
\hline Women & $591(52.2)$ \\
\hline \multicolumn{2}{|l|}{ Indications for referral* } \\
\hline Occult blood & $205(20.7)$ \\
\hline Rectal bleeding & $174(17.6)$ \\
\hline Anaemia & $353(35.7)$ \\
\hline Weight loss & $145(14.7)$ \\
\hline Change in bowel habits & $44(4.4)$ \\
\hline Abdominal pain & $148(15.0)$ \\
\hline Family history of colorectal cancer & $67(6.8)$ \\
\hline Not specified & $82(8.3)$ \\
\hline \multicolumn{2}{|l|}{ Pathological classification } \\
\hline Normal & $827(73.0)$ \\
\hline Hyperplastic polyp & $78(6.9)$ \\
\hline LGD & $133(11.7)$ \\
\hline HGD & $9(0.8)$ \\
\hline Adenocarcinoma & $38(3.4)$ \\
\hline Other & $48(4.2)$ \\
\hline \multicolumn{2}{|l|}{$\mathrm{FC} 100 \mu \mathrm{g} / \mathrm{g}(\mathrm{n}=1021)$} \\
\hline Negative & $752(73.7)$ \\
\hline Positive & $269(26.3)$ \\
\hline \multicolumn{2}{|l|}{ FIT $(n=673)$} \\
\hline Negative & $556(82.6)$ \\
\hline Positive & $117(17.4)$ \\
\hline
\end{tabular}

FC, faecal calprotectin; FIT, faecal immunological test for hemoglobin; LGD, low grade dysplasia; HGD, high grade dysplasia. *Multiple indications possible.

\section{FIT}

In total, $17.4 \%$ of the patients had a positive FIT result (Table 1 and 2). There was no significant difference in gender distribution in the outcome of FIT, but a week correlation was found to age (Table 2). Patients with CRC had significantly more often a positive FIT than patients without CRC (P > 0.0001). However, in 34\% (10 out of 29) of the patients with CRC the FIT was negative. Also, 67\% (4 out of 6) of the patients with high grade dysplasia had a negative FIT.
The sensitivity and specificity for FIT in detecting CRC and CRC/ HGD are shown in (Table 3).

FC

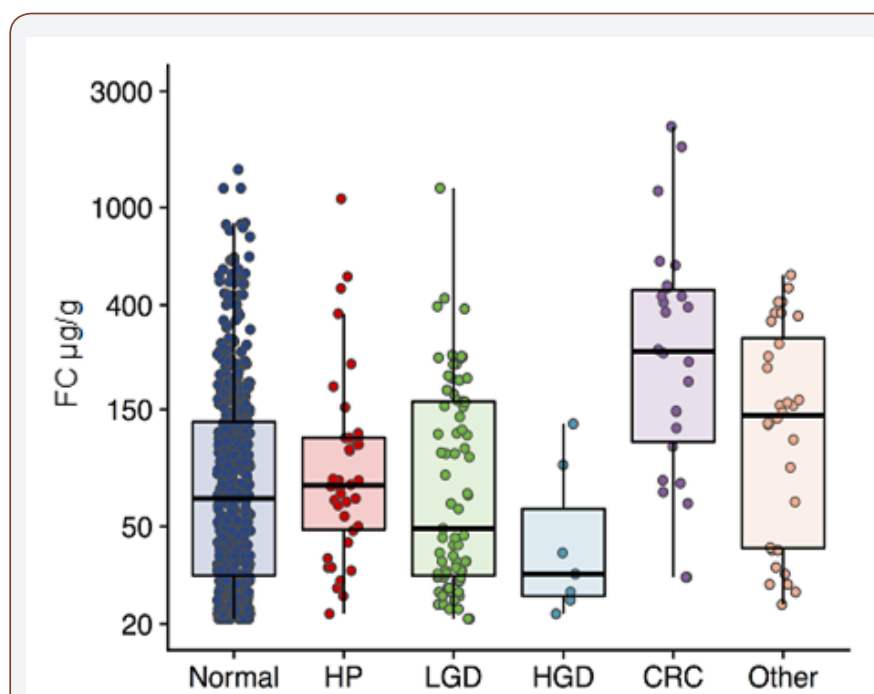

Figure 1: FC distribution according to pathological classification.

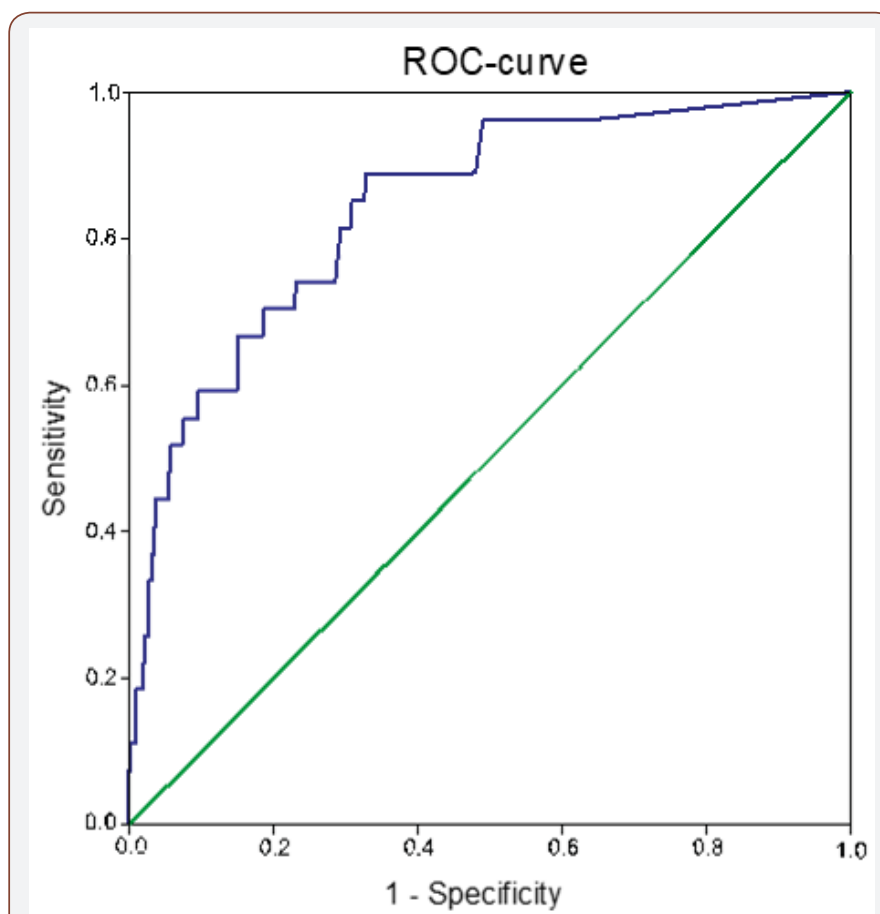

Figure 2: A ROC-curve displaying sensitivity and specificity for the FC assay in CRC detection. A cut-off value of $105.5 \mu \mathrm{g} / \mathrm{g}$ gave a sensitivity of 0.74 and a specificity of 0.76 .

The distribution of FC concentrations according to pathological classifications can be found in (Figure 1). A ROC curve analysis revealed that the most accurate cut-off level for $\mathrm{FC}$ in detecting CRC in our study was $105.5 \mu \mathrm{g} / \mathrm{g}$ (Figure 2), which is close to the commonly used cut-off value $(\leq 100 \mu \mathrm{g} / \mathrm{g})$ in clinic today. The proportion of subjects with a FC $>100 \mu \mathrm{g} / \mathrm{g}$ was significantly higher in older patients and in patients with CRC (Table 2). A cut-off of $>100 \mu \mathrm{g} / \mathrm{g}$ resulted in a sensitivity of $74.1 \%$ and a specificity of $74.9 \%$ (Table 3). Seventy-four percent (20 out of 27) of the patients with CRC had an FC > $100 \mu \mathrm{g} / \mathrm{g}$, while only 11\% (1 out of 9) with high grade dysplasia had elevated FC levels (Table 2). When using 
a lower cut-off for FC ( $>50 \mu \mathrm{g} / \mathrm{g}$ ) the sensitivity to detect CRC to $55.6 \%$, but increased specificity to $89.7 \%$. The sensitivity and increased to $88.9 \%$, but specificity was reduced to $61.8 \%$ (Table specificity for FC to detect CRC/HGD is shown in (Table 3).

3). Using a higher cut-off ( $>200 \mu \mathrm{g} / \mathrm{g}$ ) instead decreased sensitivity

Table 2: Characteristics of study patients according to FIT and FC, and the combination of FIT and FC (FIT/FC).

\begin{tabular}{|c|c|c|c|c|c|c|c|c|c|c|}
\hline & \multicolumn{3}{|c|}{ FIT n (\%) } & \multicolumn{3}{|c|}{ FC n (\%) } & \multicolumn{4}{|c|}{ FIT/FC n (\%) } \\
\hline & Negative & Positive & $\mathbf{P}$ & $\begin{array}{l}\text { Negative } \\
\leq 100 \mu \mathrm{g} / \mathrm{g}\end{array}$ & $\begin{array}{l}\text { Positive } \\
>100 \mu \mathrm{g} / \mathrm{g}\end{array}$ & $\mathbf{P}$ & $\begin{array}{l}\text { Both tests } \\
\text { negative }\end{array}$ & $\begin{array}{l}\text { At least one } \\
\text { test positive }\end{array}$ & $\begin{array}{l}\text { Both tests } \\
\text { positive }\end{array}$ & $\mathbf{P}$ \\
\hline Age category (\%) & & & 0.026 & & & $<0.0001$ & & & & $<0.0001$ \\
\hline$<59$ & $195(35.1)$ & $28(23.9)$ & & $303(40.3)$ & $48(17.8)$ & & $158(42.5)$ & 29 (19.7) & $13(31.0)$ & \\
\hline $60-69$ & $190(34.2)$ & 37 (31.6) & & $254(33.8)$ & $90(33.5)$ & & $129(34.7)$ & $51(34.7)$ & $9(21.4)$ & \\
\hline $70-79$ & $140(25.2)$ & $43(36.8)$ & & $159(21.1)$ & $105(39.0)$ & & $69(18.5)$ & $53(36.1)$ & $18(42.9)$ & \\
\hline$>80$ & $31(5.6)$ & $9(7.7)$ & & $36(4.8)$ & $26(9.7)$ & & $16(4.3)$ & $14(9.5)$ & $2(4.8)$ & \\
\hline Gender (\%) & & & 0.153 & & & 0.829 & & & & 0.663 \\
\hline Men & $259(46.6)$ & $63(53.8)$ & & $358(47.6)$ & $126(46.8)$ & & $170(45.7)$ & 73 (49.7) & $21(50.0)$ & \\
\hline Women & $297(53.4)$ & $54(46.2)$ & & $394(52.4)$ & $143(53.2)$ & & $202(54.3)$ & $74(50.3)$ & $21(50.0)$ & \\
\hline $\begin{array}{c}\text { Pathological } \\
\text { classification (\%) }\end{array}$ & & & $<0.0001$ & & & $<0.0001$ & & & & $<0.0001$ \\
\hline Normal & $381(68.5)$ & $55(47.0)$ & & $581(77.3)$ & $184(68.4)$ & & $268(72.0)$ & $84(57.1)$ & $22(52.4)$ & \\
\hline $\begin{array}{l}\text { Hyperplastic } \\
\text { polyp }\end{array}$ & 47 (8.5) & $10(8.5)$ & & $50(6.6)$ & $15(5.6)$ & & $29(7.8)$ & $13(8.8)$ & $2(4.8)$ & \\
\hline LGD & 88 (15.8) & $25(21.4)$ & & $83(11.0)$ & $28(10.4)$ & & $57(15.3)$ & $30(20.4)$ & $4(9.5)$ & \\
\hline HGD & $4(0.7)$ & $2(1.7)$ & & $8(1.1)$ & $1(0.4)$ & & $3(0.8)$ & $3(2.0)$ & $0(0.0)$ & \\
\hline CRC & $10(1.8)$ & $19(16.2)$ & & $7(0.9)$ & $20(7.4)$ & & $1(0.3)$ & $7(4.8)$ & $10(23.8)$ & \\
\hline Other & $26(4.7)$ & $6(5.1)$ & & $23(3.1)$ & $21(7.8)$ & & $14(3.8)$ & $10(6.8)$ & $4(9.5)$ & \\
\hline
\end{tabular}

CRC, colorectal cancer; FC, faecal calprotectin; FIT, faecal immunological test for hemoglobin; LGD, low grade dysplasia; HGD, high grade dysplasia Statistics: The $\mathrm{x} 2$ test or Fisher's exact test was used for categorical variables. P-value $<0.05$ was considered statistically significant.

Table 3: Sensitivity, specificity, positive predictive value (PPV) and negative predictive value (NPV) for CRC and CRC/HGD in study patients according to FIT, FC or combinations of FIT/FC.

\begin{tabular}{|c|c|c|c|c|c|c|c|c|}
\hline \multirow{2}{*}{} & \multicolumn{2}{|c|}{ Sensitivity (\%) } & \multicolumn{2}{|c|}{ Specificity (\%) } & \multicolumn{2}{|c|}{ PPV (\%) } & \multicolumn{2}{c|}{ NPV (\%) } \\
\cline { 2 - 8 } & CRC & CRC/HGD & CRC & CRC/HGD & CRC & CRC/HGD & CRC & CRC/HGD \\
\hline FIT & 65.5 & 60 & 84.8 & 85 & 16.2 & 17.9 & 98.2 & 97.5 \\
\hline FC $>50 \mu \mathrm{g} / \mathrm{g}$ & 88.9 & 72.2 & 61.8 & 61.6 & 5.9 & 6.4 & 99.5 & 98.4 \\
\hline FC $>100 \mu \mathrm{g} / \mathrm{g}$ & 74.1 & 58.3 & 74.9 & 74.8 & 7.4 & 7.8 & 99.1 & 98 \\
\hline FC $>200 \mu \mathrm{g} / \mathrm{g}$ & 55.6 & 41.7 & 89.7 & 89.6 & 12.8 & 12.8 & 98.7 & 97.7 \\
\hline At least one positive test & & & & & & & & \\
\hline FIT/FC $>50 \mu \mathrm{g} / \mathrm{g}$ & 94.4 & 83.3 & 58.6 & 58.7 & 7 & 9.3 & 99.7 & 98.7 \\
\hline FIT/FC $>100 \mu \mathrm{g} / \mathrm{g}$ & 94.4 & 83.3 & 68.3 & 68.5 & 9 & 10.6 & 99.7 & 98.9 \\
\hline FIT/FC $>200 \mu \mathrm{g} / \mathrm{g}$ & 94.4 & 79.2 & 79.4 & 79.5 & 13.2 & 14.7 & 99.8 & 98.8 \\
\hline Both tests positive & & & & & & & & \\
\hline FIT/FC $>50 \mu \mathrm{g} / \mathrm{g}$ & 72.2 & 54.2 & 92.4 & 92.4 & 24.1 & 24.1 & 99 & 97.8 \\
\hline FIT/FC $>100 \mu \mathrm{g} / \mathrm{g}$ & 55.6 & 41.7 & 94.1 & 94 & 23.8 & 23.8 & 98.5 & 97.3 \\
\hline FIT/FC $>200 \mu \mathrm{g} / \mathrm{g}$ & 38.9 & 29.2 & 97.1 & 97 & 30.4 & 30.4 & 98 & 96.8 \\
\hline
\end{tabular}

CRC, colorectal cancer; HGD, high grade dysplasia.

\section{The combined FIT and FC test}

The sensitivity and negative predictive value (NPV) improved when combining the FIT and FC test (at least one positive test) (Table 3). Ninety-four percent (17 out of 18) of the patients with CRC had at least one positive test for the two markers. A test combining FIT and FC (at least one positive test) had a sensitivity of $94.4 \%$ and a specificity of $68.3 \%$. The sensitivity and NPV did not differ for the different "FC cut-offs" but specificity and positive predictive value (PPV) was higher for $\mathrm{FC}>200 \mu \mathrm{g} / \mathrm{g}$. Instead, a test combining FIT and FC (both tests positive) for CRC had a higher specificity (94.1\%), but the sensitivity was decreased to $55.6 \%$ (Table 3). For this test, an FC cut-off of $>50 \mu \mathrm{g} / \mathrm{g}$ gave the highest sensitivity. Again, the sensitivity for detecting both CRC and HGD was generally lower than for detecting CRC alone (Table 3). 


\section{Discussion}

This study aimed to test the combination of FC and FIT in the detection of CRC in out-patients referred for colonoscopy. The FC test using the cut-off $>100 \mu \mathrm{g} / \mathrm{g}$, showed a slightly better sensitivity (74\%) in detecting CRC than FIT (66\%), but at the cost of a poorer specificity (75\% compared to $85 \%$ ). In addition, the proportion of patients with $\mathrm{FC}>100 \mu \mathrm{g} / \mathrm{g}$ was low in subjects with precancerous colonic lesions. When creating a combined model of FIT and FC (cut off $>100 \mu \mathrm{g} / \mathrm{g}$ ), where a positive score was given to patients positive for at least one of the markers, the sensitivity for CRC increased to $94 \%$. The specificity for the combined model (at least one positive test) was acceptable (68\%). The accuracy of a test as an adequate marker of disease depends on the used detection level (cut-off). A low cut-off level improves sensitivity but often at the cost of a lower specificity [34]. Also, in our study, a low cut-off level for calprotectin ( $>50 \mu \mathrm{g} / \mathrm{g}$ ), when used as a single test, improved sensitivity but decreased specificity for CRC. In general, there are two strategies for detecting CRC using faecal markers. One option is using a single sensitive marker with a high NPV, but often such a test also will have a low specificity and a low PPV [34]. An alternative is to select markers that alone are insufficiently sensitive but in combination have improved sensitivity. The rational of combining F-Hb and FC is that CRCs that due to intermittent bleeding are not detected by F-Hb tests, may still be detected by the combined test due to a possible low-grade inflammation at the tumour. In (Table 4), we present data on studies that have evaluated different methods for combining $\mathrm{F}-\mathrm{Hb}$ tests and FC tests in detection of CRC. In three of these studies no additional benefit was found for the combined test $[31,34,35]$, but in our study and three others the sensitivity increased when combining F-Hb and FC tests $[36,37,24]$. The challenge is to find the most accurate cut-off level for the specific method used. Combining the right mix of markers with adequate cut-off levels may lead to a highly sensitive test with retained specificity. There are several FC tests on the market using different methods (ELISA, fluorescence enzyme immunoassay, immunochromatography), different antibodies (monoclonal or polyclonal) and different measuring ranges that makes its hazardous to translate test results between different methods [38]. For example, the Bühlmann method shows higher values of calprotectin than the other FC methods [39]. There are also other factors that influence the outcome of a faecal test, such as accidental dilution by water/urine [38] and the transit time in colon [40]. There is still uncertainty of the most accurate cutoff value for $\mathrm{FC}$ and how to interpret intermediate values [38]. It is therefore, important to generate functional cut-off levels for FC methods in clinical practice. For the CALPRO ${ }^{\circ}$ Calprotectin ELISA Test used in the present study the most accurate cut-off level of FC to detect CRC was $105.5 \mu \mathrm{g} / \mathrm{g}$. For a combined test of FIT and FC (at least one positive marker), a cut-off for $\mathrm{FC}$ of $>200 \mu \mathrm{g} / \mathrm{g}$ gave a more specific test, while for the combined FIT/FC test (both markers positive) a reduced cut-off for $\mathrm{FC}$ of $>50 \mu \mathrm{g} / \mathrm{g}$ gave a more sensitive test.

Table 4: The sensitivity and specificity for the combination (at least one positive test) of F-Hb and FC in patients with CRC.

\begin{tabular}{|c|c|c|c|c|c|c|c|c|c|c|c|}
\hline \multicolumn{3}{|c|}{ Faecal marker method and cut-off } & \multirow{2}{*}{$\begin{array}{l}\text { CRC } \\
\text { cases } \\
\text { (n) }\end{array}$} & \multirow{2}{*}{$\begin{array}{l}\text { Control } \\
\text { subjects } \\
\text { (n) }\end{array}$} & \multicolumn{3}{|c|}{ Sensitivity (\%) } & \multicolumn{3}{|c|}{ Specificity (\%) } & \multirow[b]{2}{*}{ Comments } \\
\hline & FC & F-Hb & & & FC & $\mathrm{F}-\mathrm{Hb}$ & $\begin{array}{c}\text { FC/ } \\
\text { F-Hb }\end{array}$ & FC & $\mathrm{F}-\mathrm{Hb}$ & $\begin{array}{r}\mathrm{FC} / \\
\mathrm{F}-\mathrm{Hb}\end{array}$ & \\
\hline $\begin{array}{l}\text { Tibble } \\
2001\end{array}$ & $\begin{array}{c}\text { ELISA test } \\
\text { Quantitative test } \\
\text { cut-off }>50 \mu \mathrm{g} / \mathrm{g}\end{array}$ & gFOBT 3 samples & 62 & 229 & 90 & 58 & 90 & 72 & 92 & NA & $\begin{array}{l}\text { Two different groups in- } \\
\text { cluded (known CRC cases } \\
\text { and patients referred to } \\
\text { endoscopy) }\end{array}$ \\
\hline $\begin{array}{l}\text { Hoff } \\
2004\end{array}$ & $\begin{array}{c}\text { PhiCal test } \\
\text { Quantitative test } \\
\text { cut-off }>50 \mu \mathrm{g} / \mathrm{g}\end{array}$ & $\begin{array}{c}\text { gFOBT (Hemocult II) } 3 \\
\text { samples }\end{array}$ & 12 & 654 & 67 & 75 & 92 & 75 & 88 & NA & $\begin{array}{l}\text { CRC colonoscopy screen- } \\
\text { ing cohort }\end{array}$ \\
\hline $\begin{array}{l}\text { Parente } \\
2012\end{array}$ & $\begin{array}{l}\text { Bühlman ELISA } \\
\text { Quantitative test } \\
\text { cut-off }>50 \mu \mathrm{g} / \mathrm{g}\end{array}$ & $\begin{array}{l}\text { FIT cut }- \text { off } \geq 100 \mathrm{ng} / \\
\text { mL single sample }\end{array}$ & 47 & 233 & 86 & 62 & 91 & 40 & 89 & 36 & $\begin{array}{l}\text { Patients referred to colo- } \\
\text { noscopy Patients with IBD } \\
\text { excluded }\end{array}$ \\
\hline $\begin{array}{c}\text { Kok } \\
2012\end{array}$ & $\begin{array}{l}\text { Bühlman ELISA } \\
\text { Quantitative test } \\
\text { cut-off }>50 \mu \mathrm{g} / \mathrm{g}\end{array}$ & $\begin{array}{l}\text { FIT Clearview > } 6 \mu \mathrm{g} / \mathrm{g} \\
\text { single sample }\end{array}$ & 19 & 363 & 95 & 84 & 95 & NA & NA & NA & $\begin{array}{l}\text { Primary care Patients with } \\
\text { IBD included }\end{array}$ \\
\hline $\begin{array}{l}\text { Mowat } \\
2016\end{array}$ & $\begin{array}{l}\text { Bühlman Quanti- } \\
\text { tative test cut-off } \\
\quad>50 \mu \mathrm{g} / \mathrm{g}\end{array}$ & $\begin{array}{l}\text { FIT OC- senosor (Eiken } \\
\text { chemical co.) cut-off } \\
\text { detectable Hb single } \\
\text { sample }\end{array}$ & 28 & 727 & 82 & 100 & 100 & 39 & 43 & 20 & $\begin{array}{l}\text { Patients referred from } \\
\text { primary care. Patients } \\
\text { with IBD included }\end{array}$ \\
\hline $\begin{array}{l}\text { Högberg } \\
2017\end{array}$ & $\begin{array}{c}\text { CALPRO ELISA } \\
\text { Quantitative test } \\
\text { cut off }>100 \mu \mathrm{g} / \mathrm{g} \\
\end{array}$ & $\begin{array}{l}\text { FIT cut-off }>50 \mathrm{ng} / \mathrm{mL} \\
3 \text { samples }\end{array}$ & 8 & 365 & 50 & 88 & 88 & 85 & 67 & 61 & $\begin{array}{l}\text { Primary care Patients with } \\
\text { IBD included }\end{array}$ \\
\hline $\begin{array}{l}\text { Widlak } \\
2017\end{array}$ & $\begin{array}{c}\text { EliA immunoas- } \\
\text { say Quantitiative } \\
\text { test cut-off }>50 \\
\mu \mathrm{g} / \mathrm{g}\end{array}$ & $\begin{array}{l}\text { FIT HM-JACKarc ana- } \\
\text { lyzer (Kyowa Medex) > } \\
7 \mu \mathrm{g} / \mathrm{g} \text { single sample }\end{array}$ & 25 & 405 & 68 & 84 & 84 & 84 & 93 & 93 & $\begin{array}{l}\text { Patients referred to colo- } \\
\text { noscopy Patients with IBD } \\
\text { included }\end{array}$ \\
\hline $\begin{array}{l}\text { Eklöf } \\
\text { (present } \\
\text { study) }\end{array}$ & $\begin{array}{c}\text { CALPRO ELISA } \\
\text { Quantitaive test } \\
\text { cut off }>100 \mu \mathrm{g} / \mathrm{g} \\
\end{array}$ & $\begin{array}{l}\text { FIT cut off }>40 \mathrm{ng} / \mathrm{mL} \\
\text { single sample }\end{array}$ & 18 & 561 & 74 & 66 & 94 & 75 & 85 & 68 & $\begin{array}{l}\text { Patients referred to colo- } \\
\text { noscopy Patients with IBD } \\
\text { excluded }\end{array}$ \\
\hline
\end{tabular}

CRC, colorectal cancer; FC, faecal calprotectin; F-Hb, faecal hemoglobin; gFOBT, guaiac based faecal occult blood tests; FIT, faecal immunological test for hemoglobin; IBD, inflammatory bowel disease; NA, not available; FC/F-Hb, combined test with at least at least one marker positive. 
In our study, FIT was only analysed once, which follows the European guidelines. Repeated tests have not shown better sensitivity or specificity than one single test $[41,42,23,43,44]$. In addition, in our setup FIT and FC were analysed from stool samples collected from the same defecation. A limitation of our study was that a significant number of patients only collected a single tube before the bowel preparation. Therefore, the number of patients who had data on both FC and FIT was lower than we expected. The study cohort represents patients referred to colonoscopy from primary care. The decision of referral was made for various reasons influenced by both patients and physicians. The data for specificity and PPV must therefore be interpreted with caution and cannot directly be translated to a general population, for example in the setting of CRC screening. A major and important challenge is to find markers that could detect premalignant lesions in the colon. Unfortunately, neither FIT nor FC can successfully discriminate dysplastic adenomas from benign findings with acceptable specificity and PPV. With very low cut-off for F-Hb and FC, good sensitivity for adenomas with high grade dysplasia can be achieved but with poor specificity and PPV values [34]. Adding additional markers to F-Hb and FC may improve specificity. For example, the tumour marker M2-PK (dimeric form of pyruvate kinase) was used in combination with FIT and FC with acceptable sensitivity and specificity $[24,45]$. Also, other evolving markers have been tested with promising results $[46,25]$.

\section{Conclusion}

The combination of FIT and the FC test improves the detection of CRC. However, there is still a need for further studies using larger patient cohorts to find the optimal cut-off levels for different combination of tests.

\section{Acknowledgement}

The authors are thankful to the patients who participated in the study, and to the staff at the Endoscopy unit, Umea University Hospital, Umea, Sweden. We further thank Kerstin Näslund for technical assistance and Robin Myte for help with illustrations. This work was supported financially by the Swedish Cancer Foundation (CAN 2017/753) and the Cancer Research Foundation in Northern Sweden (AMP 11-664).

\section{Compliance with Ethical Standards}

Conflict of interest: The authors declare that they have no conflict of interest.

Ethical Approval: All procedures involving human participants were approved by the Research Ethics Committee of Umeå University, Umeå, Sweden and in accordance with the Helsinki declaration.

Informed Consent: Informed consent was obtained from al individual participants included in the study.

\section{References}

1. Mansson J, Bjorkelund C, Hultborn R (1999) Symptom pattern and diagnostic work-up of malignancy at first symptom presentation as related to level of care. A retrospective study from the primary health care centre area of Kungsbacka, Sweden. Neoplasma 46(2): 93-99.
2. Carlsson L, Hakansson A, Nordenskjold B (2001) Common cancerrelated symptoms among GP patients. Opportunistic screening in primary health care. Scand J Prim Health Care 19(3): 199-203.

3. Vandvik PO, Kristensen P, Aabakken L, Farup PG (2004) Abdominal complaints in general practice. Scand J Prim Health Care 22(3): 157-162.

4. Astin M, Griffin T, Neal RD, Rose P, Hamilton W, et al. (2011) The diagnostic value of symptoms for colorectal cancer in primary care: a systematic review. Br J Gen Pract 61(586): e231-e243.

5. Winawer SJ, Zauber AG, Ho MN, O Brien MJ, Gottlieb LS, et al. (1993) Prevention of colorectal cancer by colonoscopic polypectomy. The National Polyp Study Workgroup. N Engl J Med 329(27): 1977-1981.

6. Adler A, Roll S, Marowski B, Drossel R, Rehs HU, et al. (2007) Appropriateness of colonoscopy in the era of colorectal cancer screening: a prospective, multicenter study in a private-practice setting (Berlin Colonoscopy Project 1, BECOP 1). Dis Colon Rectum 50(10): 1628-1638.

7. Inadomi JM (2017) Screening for Colorectal Neoplasia. The New England journal of medicine 376(16): 1599-1600.

8. Robinson MH, Hardcastle JD, Moss SM, Amar SS, Chamberlain JO, et al. (1999) The risks of screening: data from the Nottingham randomised controlled trial of faecal occult blood screening for colorectal cancer. Gut 45(4): 588-592.

9. Itzkowitz S, Brand R, Jandorf L, Durkee K, Millholland J, et al. (2008) A simplified, noninvasive stool DNA test for colorectal cancer detection. Am J Gastroenterol 103(11): 2862-2870.

10. Dong Y, Wu WK, Wu CW, Sung JJ, Yu J, et al. (2011) MicroRNA dysregulation in colorectal cancer: a clinical perspective. Br J Cancer 104(6): 893-898.

11. Tagore KS, Levin TR, Lawson MJ (2004) The evolution to stool DNA testing for colorectal cancer. Aliment Pharmacol Ther 1 (12): 1225-1233.

12. Young GP, Cole S (2007) New stool screening tests for colorectal cancer Digestion 76(1): 26-33.

13. Brenner DJ, Georgsson MA (2005) Mass screening with CT colonography: should the radiation exposure be of concern? Gastroenterology 129(1): 328-337.

14. Herzog P, Holtermuller KH, Preiss J, Fischer J, Ewe K, et al. (1982) Fecal blood loss in patients with colonic polyps: a comparison of measurements with 51chromium-labeled erythrocytes and with the Haemoccult test. Gastroenterology 83(5): 957-962.

15. Macrae FA, St John DJ (1982) Relationship between patterns of bleeding and Hemoccult sensitivity in patients with colorectal cancers or adenomas. Gastroenterology 82(5 Pt 1): 891-898.

16. Lenhard K, Bommer GT, Asutay S, Schauer R, Brabletz T, et al. (2005) Analysis of promoter methylation in stool: a novel method for the detection of colorectal cancer. Clin Gastroenterol Hepatol 3(2): 142-149.

17. Allison JE, Tekawa IS, Ransom LJ, Adrain AL (1996) Improving the fecal occult-blood test. The New England journal of medicine 334(24): 16071608.

18. Lieberman DA, Weiss DG (2001) One-time screening for colorectal cancer with combined fecal occult-blood testing and examination of the distal colon. The New England journal of medicine 345(8): 555-560.

19. Allison JE (2007) Should recommendations for colorectal-cancer screening be changed. Nat Clin Pract Oncol 4(7): 392-393.

20. Morikawa T, Kato J, Yamaji Y, Wada R, Mitsushima T, et al. (2005) A comparison of the immunochemical fecal occult blood test and total colonoscopy in the asymptomatic population. Gastroenterology 129(2): 422-428.

21. Smith A, Young GP, Cole SR, Bampton P (2006) Comparison of a brushsampling fecal immunochemical test for hemoglobin with a sensitive guaiac-based fecal occult blood test in detection of colorectal neoplasia. Cancer 107(9): 2152-2159.

22. Quintero E, Castells A, Bujanda L, Cubiella J, Salas D, et al. (2012) Colonoscopy versus fecal immunochemical testing in colorectal-cancer screening. N Engl J Med 366(8): 697-706.

23. Lee JK, Liles EG, Bent S, Levin TR, Corley DA, et al. (2014) Accuracy of fecal immunochemical tests for colorectal cancer: systematic review and meta-analysis. Ann Intern Med 160(3): 171. 
24. Parente F, Marino B, Ilardo A, Fracasso P, Zullo A, et al. (2012) A combination of faecal tests for the detection of colon cancer: a new strategy for an appropriate selection of referrals to colonoscopy? A prospective multicentre Italian study. European journal of gastroenterology \& hepatology 24(10): 1145-1152.

25. Eklof V, Lofgren-Burstrom A, Zingmark C, Edin S, Larsson P, et al. (2017) Cancer-associated fecal microbial markers in colorectal cancer detection. Int J Cancer 141(12): 2528-2536.

26. Roseth AG, Fagerhol MK, Aadland E, Schjonsby H (1992) Assessment of the neutrophil dominating protein calprotectin in feces. A methodologic study. Scand J Gastroenterol 27(9): 793-798.

27. Roseth AG, Kristinsson J, Fagerhol MK, Schjonsby H, Aadland E, et al (1993) Faecal calprotectin: a novel test for the diagnosis of colorectal cancer. Scand J Gastroenterol 28(12): 1073-1076.

28. Kristinsson J, Roseth A, Fagerhol MK, Aadland E, Schjonsby H, et al. (1998) Fecal calprotectin concentration in patients with colorectal carcinoma. Dis Colon Rectum 41(3): 316-321.

29. Kronborg O, Ugstad M, Fuglerud P, Johne B, Hardcastle J, et al. (2000) Faecal calprotectin levels in a high-risk population for colorectal neoplasia. Gut 46(6): 795-800.

30. Kristinsson J, Armbruster CH, Ugstad M, Kriwanek S, Nygaard K, et al (2001) Fecal excretion of calprotectin in colorectal cancer: relationship to tumor characteristics. Scand J Gastroenterol 36(2): 202-207.

31. Widlak MM, Thomas CL, Thomas MG, Tomkins C, Smith S, et al. (2017) Diagnostic accuracy of faecal biomarkers in detecting colorectal cancer and adenoma in symptomatic patients. Aliment Pharmacol Ther 45(2): 354-363.

32. Lehmann FS, Trapani F, Fueglistaler I, Terracciano LM, Von Flue M, et al. (2014) Clinical and histopathological correlations of fecal calprotectin release in colorectal carcinoma. World J Gastroenterol 20(17): 49944999.

33. Gilbert JA, Ahlquist DA, Mahoney DW, Zinsmeister AR, Rubin J, et al. (1996) Fecal marker variability in colorectal cancer: calprotectin versus hemoglobin. Scand J Gastroenterol 31(10): 1001-1005.

34. Mowat C, Digby J, Strachan JA, Wilson R, Carey FA, et al. (2016) Faeca hemoglobin and faecal calprotectin as indicators of bowel disease in patients presenting to primary care with bowel symptoms. Gut 65(9): 1463-1469.

35. Hogberg C, Soderstrom L, Lilja M (2017) Faecal immunochemical tests for the diagnosis of symptomatic colorectal cancer in primary care: the benefit of more than one sample. Scand J Prim Health Care 35(4): 369 372.
36. Hoff G, Grotmol T, Thiis-Evensen E, Bretthauer M, Gondal G, et al. (2004) Testing for faecal calprotectin (PhiCal) in the Norwegian Colorectal Cancer Prevention trial on flexible sigmoidoscopy screening: comparison with an immunochemical test for occult blood (FlexSure OBT). Gut 53(9): 1329-1333.

37. Kok L, Elias SG, Witteman BJ, Goedhard JG, Muris JW, et al. (2012) Diagnostic accuracy of point-of-care fecal calprotectin and immunochemical occult blood tests for diagnosis of organic bowel disease in primary care: the Cost-Effectiveness of a Decision Rule for Abdominal Complaints in Primary Care (CEDAR) study. Clin Chem 58(6): 989-998.

38. Manceau H, Chicha-Cattoir V, Puy H, Peoc'h K (2017) Fecal calprotectin in inflammatory bowel diseases: update and perspectives. Clin Chem Lab Med 55(4): 474-483.

39. Amcoff K, Stridsberg M, Lampinen M, Magnuson A, Carlson M, et al. (2017) Clinical implications of assay specific differences in f-calprotectin when monitoring inflammatory bowel disease activity over time. Scand J Gastroenterol 52(3): 344-350.

40. Lasson A, Stotzer PO, Ohman L, Isaksson S, Sapnara M, et al. (2015) The intra-individual variability of faecal calprotectin: a prospective study in patients with active ulcerative colitis. J Crohns Colitis 9(1): 26-32.

41. Halloran SP, Launoy G, Zappa M (2012) European guidelines for quality assurance in colorectal cancer screening and diagnosis. First Edition-Faecal occult blood testing. Endoscopy 44 Suppl 3: SE65-87.

42. Carroll MR, Seaman HE, Halloran SP (2014) Tests and investigations for colorectal cancer screening. Clin Biochem 47(10-11): 921-939.

43. Allison JE, Fraser CG, Halloran SP, Young GP (2014) Population screening for colorectal cancer means getting FIT: the past, present, and future of colorectal cancer screening using the fecal immunochemical test for hemoglobin (FIT). Gut Liver 8(2): 117-130.

44. Whitlock EP, Lin JS, Liles E, Beil TL, Fu R, et al. (2008) Screening for colorectal cancer: a targeted, updated systematic review for the U.S. Preventive Services Task Force. Ann Intern Med 149(9): 638-658.

45. Rutka M, Bor R, Balint A, Fabian A, Milassin A, et al. (2016) Diagnostic Accuracy of Five Different Fecal Markers for the Detection of Precancerous and Cancerous Lesions of the Colorectum. Mediators Inflamm 2016: 2492081.

46. Flanagan L, Schmid J, Ebert M, Soucek P, Kunicka T, et al. (2014) Fusobacterium nucleatum associates with stages of colorectal neoplasia development, colorectal cancer and disease outcome. Eur J Clin Microbiol Infect Dis 33(8): 1381-1390. 